\title{
コールドクルーシブルによる金属バナジウムの精錬
}

保母 誠*，坂田雅史 ${ }^{*}$, 芝田智樹*

\section{Refining of Vanadium Using Cold Crucible}

\author{
Makoto Hobo, Masafumi Sakata, and Tomoki Shibata
}

\section{Synopsis}

Vanadium is expected to be used as an element in hydrogen storage alloys. One of the main obstacles to this metal being used more commonly in this way is its cost. Pure V refined by electron beam furnace costs more than 60,000 yen/kg in Japan.

This paper aims for the realization of a cost efficient process for producing pure $V$, by refining Al-95V alloy which is almost as cheap as a tenth of pure $V$. The cold crucible was chosen as a refining furnace because it does not use ceramic crucibles, which would react with the molten vanadium and impurify it.

The combination of two successive processes was invented. In the first process, $\mathrm{Al}_{2} \mathrm{O}_{3}$ was removed by slag-metal reaction. In the second process, Misch metal was used for deoxidization. $\mathrm{Ti}_{7} \mathrm{Cr}_{12.5} \mathrm{~V}_{78.5} \mathrm{Mn}_{2}$ which was produced by this new method showed good performance as a hydrogen storage alloy.

\section{1. 緒言}

バナジウム (以下, $\mathrm{V}$ と記す) は水素吸蔵能が高く， 水素吸蔵合金への適用が期待される ${ }^{1), 2)}$ が , 純 V はコス トが高いため量産への大きな障害となる . 通常金属 V は 酸化バナジウムを $\mathrm{Al}$ で還元して粗 V としたあと電子ビー ム溶解 $(\mathrm{EB})^{3)}$ で $\mathrm{Al}, \mathrm{O}$ 等の不純物を除去して製造されるも ので , 高純度は得られるものの EB 溶解を経るため非常に 高価なもの（市場価格約 60,000 円/kg）になる .

したがって，低コストで高純度な V を得るためには新 たな精錬方法を開発する必要がある．V は高融点金属(融 点=約 $1890{ }^{\circ} \mathrm{C}$ ) であり，かつ鉄以上に活性であることか ら従来のるつぼを使用した精錬は非常に困難で,コスト低 減の観点からの研究はテルミット反応と組み合わせた低 $\mathrm{Al}$ 化と脱酸の例 ${ }^{2)}$ がある程度で光れ以外では，これまで あまり行なわれていない .

水素吸蔵合金として使用するためには，吸蔵特性に悪影 響を及ぼす $\mathrm{Al}$ と $\mathrm{O}$ を低減する必要がある 著者らは以前， 真空誘導炉でるつぼを用いて V のスラグ精錬を試みたが，
るつぼからの酸素污染により狙い通りの製品を得ること ができなった .光こで今回るつぼを用いないレビテーショ ン炉 ${ }^{4), 5)}$ (コールドクルーシブル) を使用し V の脱酸およ びスラグ精錬による脱 $\mathrm{Al}$ を試みたので報告する .

\section{2 . 実験方針の決定}

\section{1 V 原料}

原料の粗 V はアルミノテルミット反応 ${ }^{2)}$ で製造された 太陽鉱工(株)製の Al-V95 (価格約 6,000 円 $/ \mathrm{kg}$ ) で炎の成分 を Table 1 に示す. Al 濃度に注目すると全 Al (以下, T$\mathrm{Al}$ ) > 可溶 $\mathrm{Al}$ (以下, S-Al) となっており, 酸化物として の $\mathrm{Al}\left(\mathrm{Al}_{2} \mathrm{O}_{3}\right)$ が多く存在していることが分かる. 実際に 原料をミクロ観察すると, 数多くの $\mathrm{Al}_{2} \mathrm{O}_{3}$ 介在物が観察さ れる .

Table 1. Chemical composition of Al-V95 alloy (mass\%).

\begin{tabular}{c|c|c|c|c}
\hline Alloy & T-Al & S-Al & T-O & V \\
\hline Al-V95 & 2.32 & 0.69 & 1.64 & $>95$ \\
\hline
\end{tabular}

2.2 精錬方法の決定

今回の V は最終的には水素吸蔵合金で使用するのが目 
的である、弚のため,水素吸蔵特性に悪影響を及ぼす原料 中の $\mathrm{Al}$ と O を低減することが不可欠である . 低減值の目 標としては, 以前の研究結果や他者の報告值 2 ,6) などの知 見から，Al<0.5 mass\%, O<0.1 mass\%に設定した .

$\mathrm{V}$ 原料中の $\mathrm{O}, \mathrm{Al}$ の成分值から ( mass\% T-Al ) - ( mass\% $\mathrm{S}-\mathrm{Al}$ ) で得られる $\mathrm{Al}$ は全て $\mathrm{Al}_{2} \mathrm{O}_{3}$ であると仮定して成分 バランスを計算すると Table 2のようになる .この表から $\mathrm{Al}_{2} \mathrm{O}_{3}$ を除去すれば大部分の $\mathrm{O}$ と $\mathrm{Al}$ が低減できることが わかる. $\mathrm{Al}_{2} \mathrm{O}_{3}$ （比重 =3.97）と V (同約 5.6) には比重差 があるので $\mathrm{V}$ を溶解すれば， $\mathrm{Al}_{2} \mathrm{O}_{3}$ は浮上するはずであ る.鋼の精錬ではこのような浮上酸化物をスラグを使用し て分離する方法が一般的であるので,本研究でも $\mathrm{Al}_{2} \mathrm{O}_{3}$ を 分離除去するためにスラグ精錬を考えた .

ただしスラグ精鍊で $\mathrm{Al}_{2} \mathrm{O}_{3}$ が全量除去できたとしても， 酸素濃度は表の S-O (0.19 mass\%) になるだけである .こ れでは目標の 0.1 mass\% に届かないので, スラグ精錬と平 行して脱酸も必要だと考えられる.V 合金に対してはミッ シュメタル (以下, $\mathrm{Mm}$ と称す) $, \mathrm{Mg}, \mathrm{Ca}$ 等を脱酸元素に 用いた例が挙げられている2)が,Mmによる脱酸が最も低 酸素化を実現している．光こで本研究でも脱酸元素とし て，高い効果が期待できる $\mathrm{Mm}$ をまず選び，新たに $\mathrm{Zr} に$ ついても試みることにした .

Table 2. Calculated content of dissolved and oxidized oxygen and aluminum (mass\%).

\begin{tabular}{c|c|c|c}
\hline $\mathrm{O}$ as $\mathrm{Al}_{2} \mathrm{O}_{3}$ & $\mathrm{~S}-\mathrm{O}$ & ${\mathrm{Al} \mathrm{as} \mathrm{Al}_{2} \mathrm{O}_{3}}_{1}$ & $\mathrm{~S}-\mathrm{Al}$ \\
\hline 1.45 & 0.19 & 1.63 & 0.69 \\
\hline
\end{tabular}

\section{3 .実験方法}

\section{1 実験装置および原料}

実験に使用した装置は大同特殊鋼(獉)（以下，当社と記 す）が所有する，2 kg レビテーション溶解炉 4), 5) であり， 炉の概略を Fig.1に示す

$\mathrm{V}$ 以外の原料については, $\mathrm{Ti}$ は純 $\mathrm{Ti}$ 板屑を $, \mathrm{Cr}, \mathrm{Mn}$ は

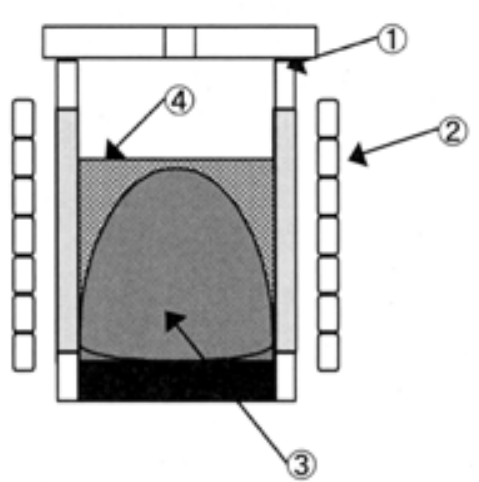

(1) Cu crucible

(2) Cu coil

(3) Molten metal

(4) Molten slag

Fig.1. Experimental apparatus.

弚れ光れ通常使用している金属 $\mathrm{Cr}$, 金属 $\mathrm{Mn}$ を使用した (Table 3) .

また実験に使用したフラックスは $\mathrm{CaO}, \mathrm{CaF}_{2}, \mathrm{Al}_{2} \mathrm{O}_{3}$ のい ずれも特級試薬を用い,あらかじめ目的の配合組成になる ように配合した後， $\varphi 15$ のタブレット状に成型して用い た .また脱酸には先に述べたとおり MmおよびZrを用いた 。

Table 3. Chemical compositions of $\mathrm{Ti}, \mathrm{Cr}, \mathrm{Mn}$ (mass\%).

\begin{tabular}{c|c|c|c|c|c}
\hline & Purity & T-Al & T-O & T-N & Fe \\
\hline Ti sheet & $>99.9$ & 0.01 & 0.046 & 0.003 & 0.029 \\
\hline Met-Cr & $>99.9$ & $<0.0010$ & 0.045 & 0.001 & 0.019 \\
\hline Met-Mn & 99.9 & - & 0.1 & 0.003 & 0.002 \\
\hline
\end{tabular}

3.2 予備実験と結果

\section{2 .1 原料溶解テスト}

原料塊個々には成分のばらつきがあると思われるので， 使用する粗 V $2 \mathrm{~kg}$ をレビテーション炉で溶解 (溶解時間 $300 \mathrm{~s})$ し, 溶解前後の成分を比較した . 結果を Table 4 に 示す. 溶解前後で O, S-Al は同等と見なせるが， T-Alにつ いては溶解後の方が少し低くなっている.よって以降の実 験では溶解後精錬前にもサンプルを採取して,精錬後との 成分比較を行なうことにした。

\subsection{2 スラグ精錬時間と脱酸平衡時間の決定}

レビテーション炉を用いたスラグ精錬に先立ち，まず初 めに必要な精錬時間を決定する必要がある . スラグは $\mathrm{CaO}-\mathrm{Al}_{2} \mathrm{O}_{3}-\mathrm{CaF}_{2}$ 系を用い, 溶解中にサンプリングを行な い, 成分の経時変化による推移を調査した . 結果を Fig.2 に示す .この図から必要な精錬時間はスラグ溶解から 300 $\mathrm{s}$ 以上と決定した .

Table 4. Oxygen and aluminum content change by melting Al-V95.

\begin{tabular}{c|c|c|c}
\hline & T-Al & S-Al & T-O \\
\hline Before melting & 2.32 & 0.69 & 1.64 \\
\hline After melting & 1.96 & 0.86 & 1.64 \\
\hline
\end{tabular}

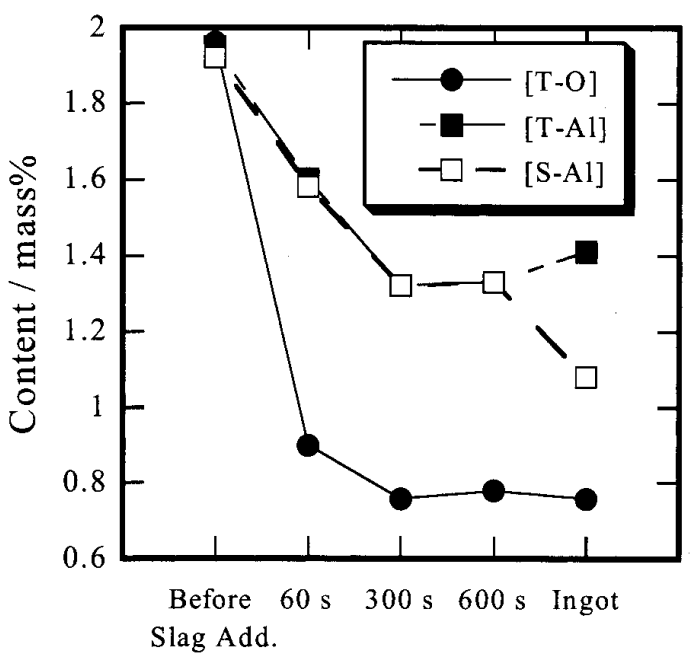

Fig.2. Content change of $\mathrm{Al}$ and $\mathrm{O}$ by slag refining. 
また，脱酸元素添加後の精錬時間も同樣に $\mathrm{Mm}$ および $\mathrm{Zr}$ 添加からの酸素濃度の推移を調査し, 添加から $60 \mathrm{~s}$ 後 と $300 \mathrm{~s}$ 後て酸素濃度はほぼ同じとなっていることから (Fig.3)60 s でほぼ平衡に到達しているものと考えたが ,多 少余裕を見て $120 \mathrm{~s}$ 以上と決定した .

\section{3 スラグによる $\mathrm{Al}_{2} \mathrm{O}_{3}$ の精錬}

ここからの実験では V の精錬と水素吸蔵合金製造の両 立を目指し $\mathrm{Ti}_{7} \mathrm{Cr}_{12.5} \mathrm{~V}_{78.5} \mathrm{Mn}_{2}$ (添字は成分の $\mathrm{mol} \%$ を表し， 以下 TiCrVMn と表記) となるように組成を調整した。実 際の手順は Fig.4 に示すように , V, Cr, Ti, Mn の順番に溶 解し全量溶解 (以下 MD と称す) 後, スラグを添加して 溶解させ , スラグ MD 後 $60 \mathrm{~s}, 300 \mathrm{~s}, 600 \mathrm{~s}$ 後に吸い上げサ ンプルを採取した . 初期のスラグ組成は Fig.4 中に示す .

\section{4 脱酸テスト}

スラグ精鍊に引き続いて脱酸元素を投入し，脱酸を行っ た (Fig.5) . 脱酸元素は二段階に分けて添加（たとえば Mm 4.0 mass\% 添加の場合，まず半分の 2.0 mass\% 添加し $120 \mathrm{~s}$ 以上経過後サンプリングし,さらに残りの 2.0 mass\% を添加) することにより，一溶解で 2 水準の結果を得た .

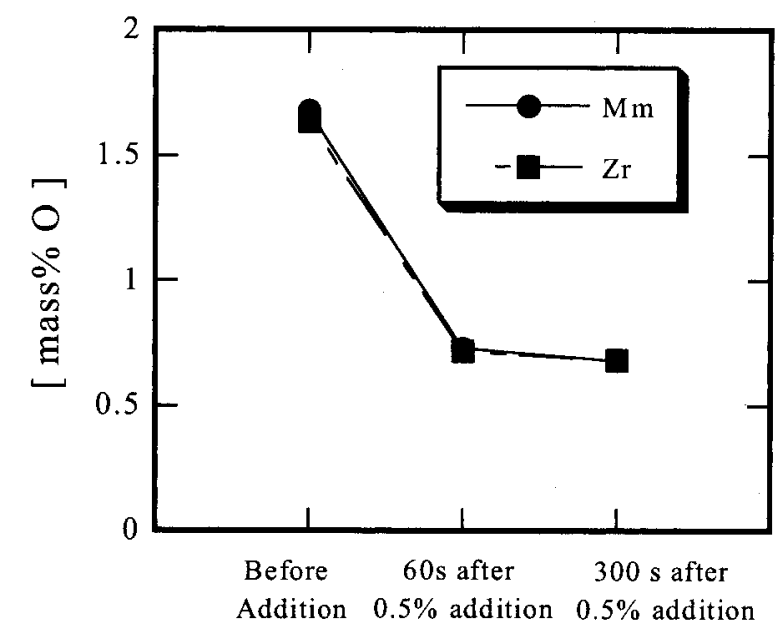

Fig.3. Content change of $\mathrm{O}$ with time after adding deoxidizing reagent.

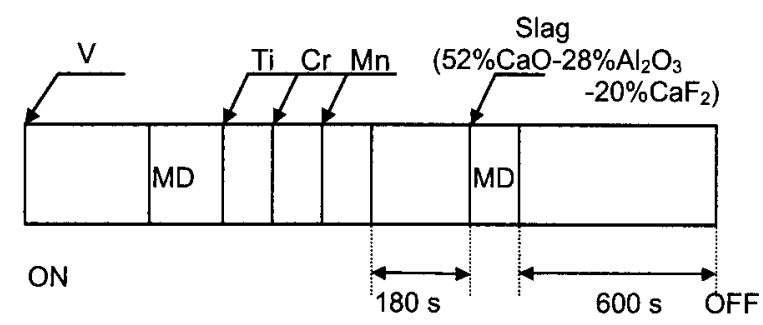

Fig.4. Melting procedure for slag refining tests.

\section{4 . 結 果}

4.1 スラグによる脱 $\mathrm{Al}_{2} \mathrm{O}_{3}$

今回の実験結果を Table 5, Table 6 に示す . Table 6 に示 した組成のスラグを使用して精錬した場合の成分推移を Fig.6に 、また比較としてスラグを使用しない場合を Fig.7 示す．O, T-Al はスラグを使用した場合の方が使用しない 場合より低減していることが分かる。

このときのスラグの成分を精錬前後で比較すると Table 6 (表の一番上のデータ) に示したようになる. $\mathrm{Al}_{2} \mathrm{O}_{3}$ の存 在比か増加しており,メタルから除去されスラグに移行し たことを表している．しかしながら得られた $\mathrm{Al}$ 濃度は最 低でも 1 mass\%を上回っており,ねらい通りに低減できて いない . また表から，メタル中に含まれる Ti のかなりの 量か酸化物となってスラグ中に移行したこともわかる .

4.2 Mm および Zr による脱酸

スラグ精鍊に引き続いて行った脱酸テストの結果を

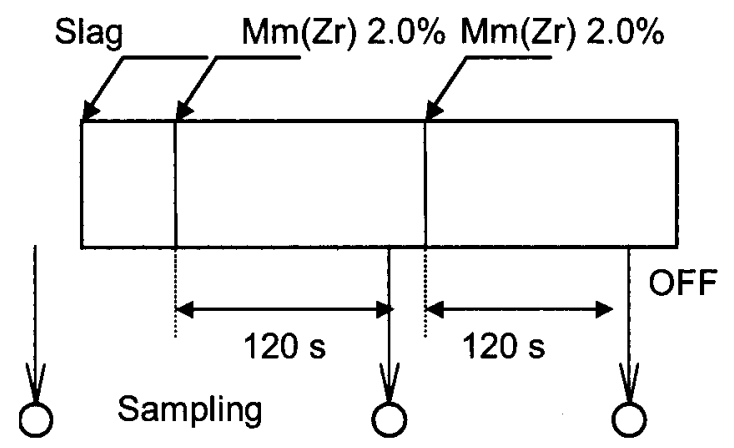

Fig.5. Melting procedure for deoxidizing tests

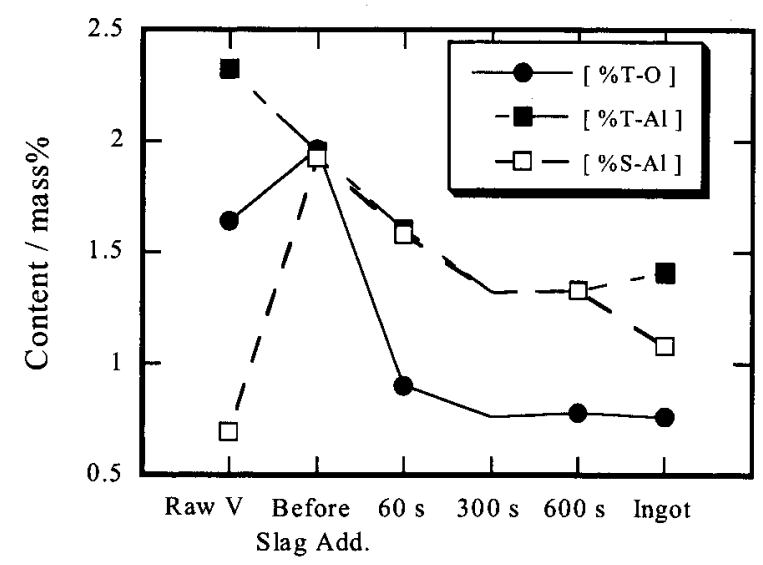

Fig.6. Content change of $\mathrm{Al}$ and $\mathrm{O}$ with slag refining compared to raw V. 
Table 5. Experimental data for slag rifining and deoxidizing tests.

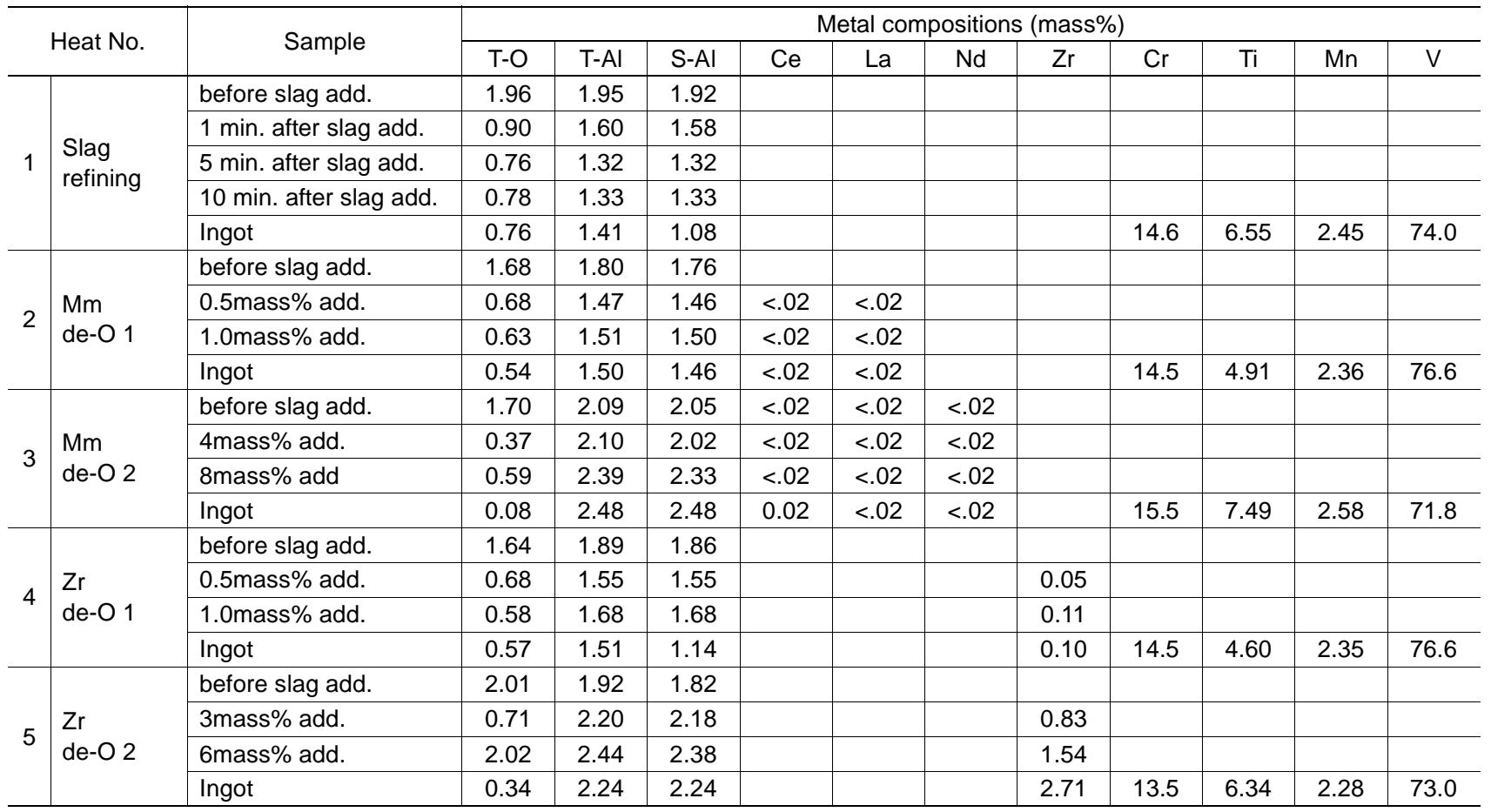

Table 6. Chemical compositions of slags used in slag refining and deoxidizing tests.

\begin{tabular}{|c|c|c|c|c|c|c|c|c|c|c|c|}
\hline \multirow{2}{*}{\multicolumn{3}{|c|}{ Heat No. }} & \multicolumn{9}{|c|}{ Slag compositions (mass\%) } \\
\hline & & & \multirow{2}{*}{$\begin{array}{l}\mathrm{CaO} \\
52.0 \\
\end{array}$} & \multirow{2}{*}{$\frac{\mathrm{Al}_{2} \mathrm{O}_{3}}{28.0}$} & \multirow[t]{2}{*}{$\mathrm{TiO}_{2}$} & \multirow{2}{*}{$\frac{\mathrm{CaF}_{2}}{20.0}$} & \multirow[t]{2}{*}{$\mathrm{V}_{2} \mathrm{O}_{5}$} & \multirow[t]{2}{*}{$\mathrm{CeO}_{2}$} & \multirow[t]{2}{*}{$\mathrm{La}_{2} \mathrm{O}_{3}$} & \multirow[t]{2}{*}{$\mathrm{Nd}_{2} \mathrm{O}_{3}$} & \multirow[t]{2}{*}{$\mathrm{ZrO}_{2}$} \\
\hline \multirow{2}{*}{1} & \multirow{2}{*}{ Slag refining } & As mixed & & & & & & & & & \\
\hline & & After refining & 35.5 & 30.2 & 21.1 & 11.4 & 1.2 & & & & \\
\hline \multirow{2}{*}{2} & \multirow{2}{*}{ Mm de-O 1} & As mixed & 52.0 & 28.0 & & 20.0 & & & & & \\
\hline & & After refining & 36.6 & 26.8 & 13.5 & 8.5 & 4.8 & 6.4 & - & 2.0 & \\
\hline \multirow{2}{*}{3} & \multirow{2}{*}{ Mm de-O 2} & As mixed & 52.0 & 28.0 & & 20.0 & & & & & \\
\hline & & After refining & 9.8 & 6.0 & 4.8 & 14.3 & 0.4 & 38.0 & 16.6 & 11.1 & \\
\hline \multirow{2}{*}{4} & \multirow{2}{*}{ Zr de-O 1} & As mixed & 52.0 & 28.0 & & 20.0 & & & & & \\
\hline & & After refining & 32.0 & 26.2 & 11.8 & 11.2 & 1.1 & & & & 16.8 \\
\hline \multirow{2}{*}{5} & \multirow{2}{*}{$\mathrm{Zr}$ de-O 2} & As mixed & 52.0 & 28.0 & & 20.0 & & & & & \\
\hline & & After refining & 33.0 & 17.8 & 9.8 & 10.8 & & & & & 24.2 \\
\hline
\end{tabular}

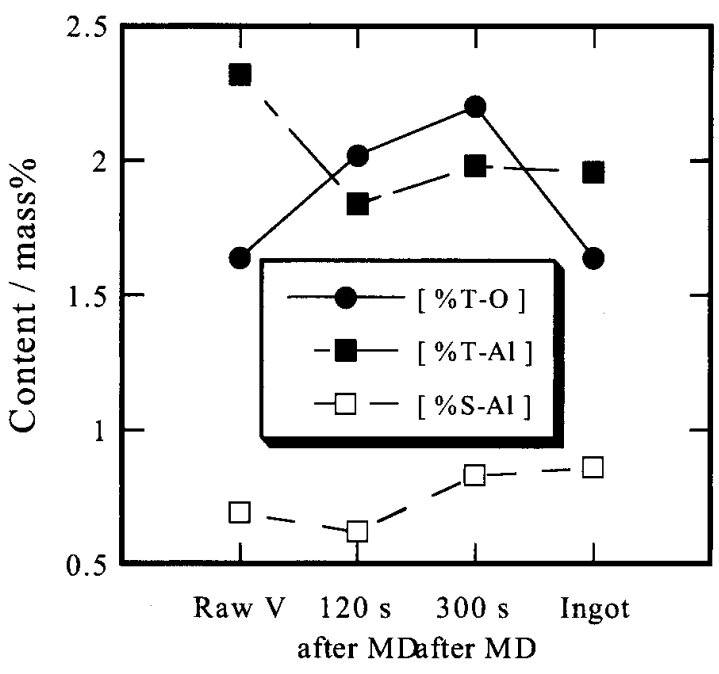

Fig.7. Content change of $\mathrm{Al}$ and $\mathrm{O}$ without slag refining.
Fig.8 , Fig.9 に示す . Fig.8 では横軸に脱酸元素の添加量 を, Fig.9 では添加後のメタル中の濃度 (分析值) を横軸 とした . Fig.8 から同じ添加量では Mm の方が若干脱酸力 が強く, 最も脱酸が進んだもので酸素濃度は 0.08 mass\% まで低減していることが分かる．また Fig.9から，Zr はか なりの量がメタル中に溶解し残留するのに対し, $\mathrm{Mm}$ は溶 解後はほとんどメタル中に残存しないことが明らかと なった。

\section{5. 考察}

\subsection{Al の挙動}

スラグ精錬の目的は 2.2 で述べたように，原料中に含ま れる $\mathrm{Al}_{2} \mathrm{O}_{3}$ をスラグ精錬で分離除去することである . 


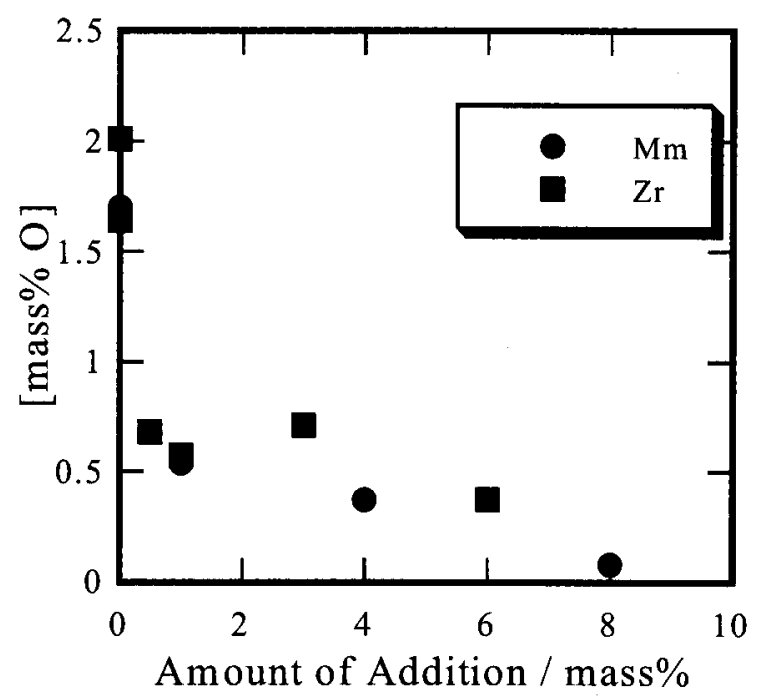

Fig.8. Relation between [mass $\%$ O] and the amount of addition of deoxidizing reagent.

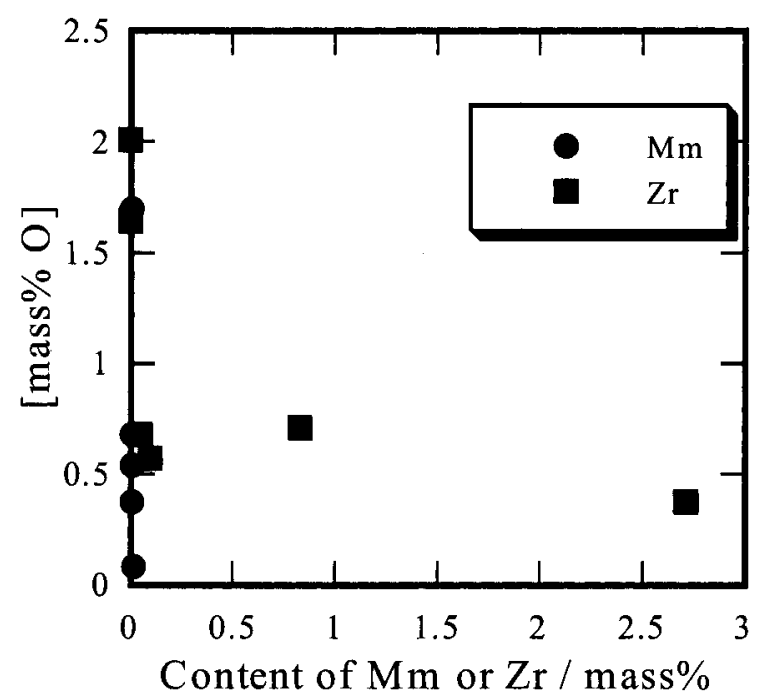

Fig.9. Relation between [mass\% O] and the analysed content of deoxidizing reagent.

Fig.10 に今回のスラグ精錬実験での $\mathrm{Al}$ の挙動を示す . 図 にはメタルとして TiCrVMn を溶解した場合と，粗 V のみ を溶解した場合を併記してある.両方を比較した場合特記 的なことは S-Al の挙動で,粗 V 溶解の時は T-Al が精錬前 と比較して下がり，S-Al はほぼ一定なのに対し，TiCrVMn を溶製した場合は S-Al か増加し T-Al と同等になることが わかる . また T-Al の值も V のみの場合ほど低下していな い.この現象は $\mathrm{Al}$ が一旦全て S-Al になることを表し，光 れはすなわちメタル中の $\mathrm{Al}_{2} \mathrm{O}_{3}$ が還元され $\mathrm{Al}$ に変化した ことに他ならない

精錬後のスラグに $\mathrm{TiO}_{2}$ が生成していることから，

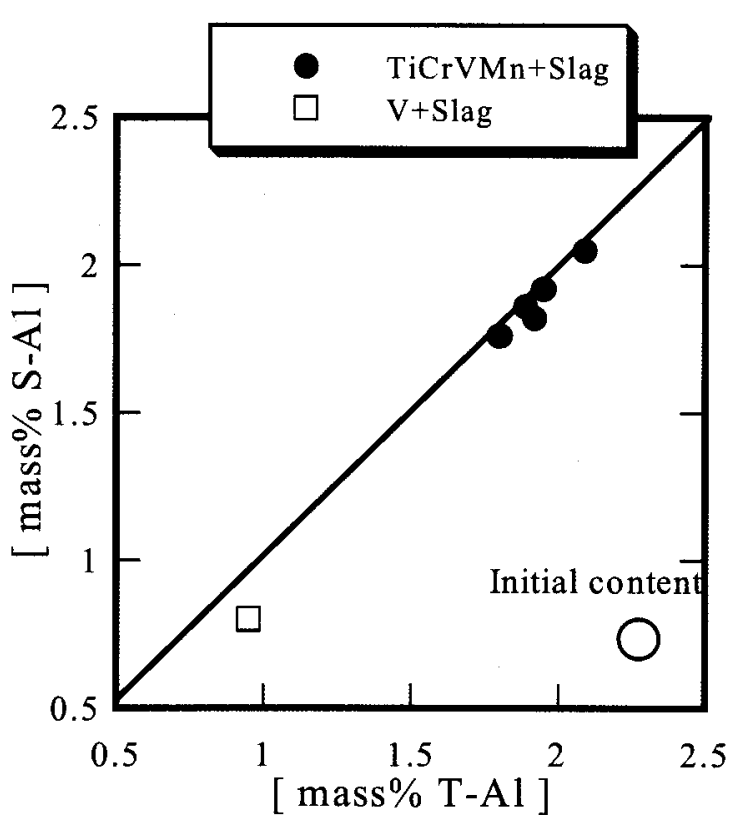

Fig.10. Relation between [mass\% T-Al] and [mass\% S-Al] after melting.

$2 \mathrm{Al}_{2} \mathrm{O}_{3}$ (in metal) $+3 \mathrm{Ti}$ (in metal)

$\rightarrow \quad 4 \mathrm{Al}($ in metal $)+3 \mathrm{TiO}_{2}$ (in slag)

の反応が起こっていることが予想される .

酸化物の標準自由エネルギーの比較では $\mathrm{Al}_{2} \mathrm{O}_{3}$ の方が安 定であるため,(1)の反応は起こりにくいように思えるが， 実際に起こったことから考えると, 溶融 V中での Ti の活 量が大きいか若しくはAlの活量が小さい事が考えられる． これらのデータがないため推定すると，V-Ti 系はほぼ全率 固溶であるため ,Ti の活量は Raoul 則からあまりずれてい ないと予想されるが，V-Al 系は多くの金属間化合物を生 成するため $\mathrm{Al}$ の活量は非常に低いことが予想される．し たがって (1) 式が起こるものと考えられる．これが，S-Al がメタル中に増加しスラグ精錬による $\mathrm{Al}_{2} \mathrm{O}_{3}$ の除去が進ま なかった理由である .

また, 脱酸テストでの $\mathrm{Al}$ の推移を見ると, 多くの場合 で精錬後に $\mathrm{Al}$ か増加している.これを表したのが Fig.11 である . 脱酸元素の添加量が多くなるほど $\mathrm{Al}$ は増加して いることが分かる．

また，精錬前後での $\mathrm{Al}$ の物質収支を取ると Fig.12のよ うになり, 確かにスラグから減少した分がメタル中に増加 した分とよく一致している.

これらのことから 脱酸元素によりスラグ中にあった $\mathrm{Al}_{2} \mathrm{O}_{3}$ の一部が還元されてメタルに戻ったものと推察される .

\section{2 ダブルメルト溶解}

以上の考察から 本合金系では (1) 溶融 $\mathrm{V}$ 原料中の $\mathrm{Al}_{2} \mathrm{O}_{3}$ 


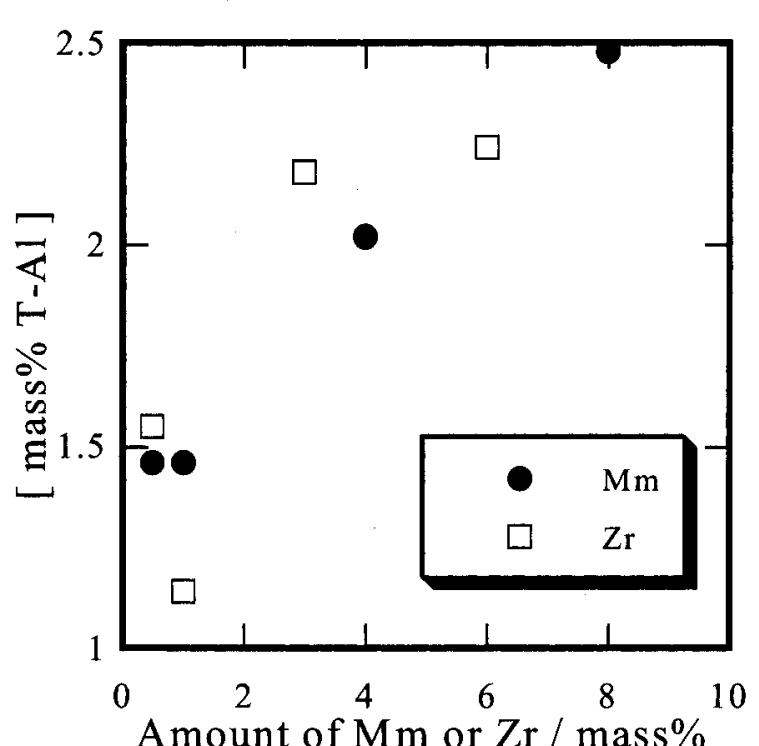

Fig.11. Increase of [mass\% T-Al] along with the amount of deoxidizing reagent.

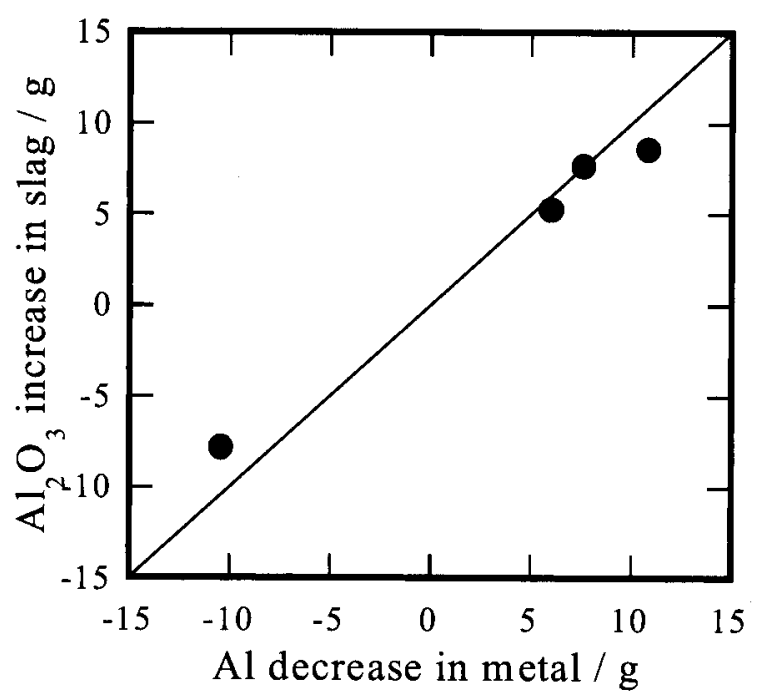

Fig.12. Mass balance of Al between metal and slag.

は ,Ti が共存すると還元され ,(2) スラグ中の $\mathrm{Al}_{2} \mathrm{O}_{3}$ は $\mathrm{Mm}$ や Zr などの脱酸元素により還元される，ことが分かった . これらのことから脱 $\mathrm{Al}$ を促進させるためには , まず $\mathrm{Ti}$ を 含まない状態でスラグによる脱 $\mathrm{Al}_{2} \mathrm{O}_{3}$ が必要で,かつ脱酸 の際にはスラグ中に $\mathrm{Al}_{2} \mathrm{O}_{3}$ を含まないことが必要条件であ ると考えられる．乥こで，この推論を証明するため，以下 のような溶解工程に分け前述のレビテーション炉で精錬 を試みた 。

Melt 1 ; 粗 V のみを溶解しスラグを用いて $\mathrm{Al}_{2} \mathrm{O}_{3}$ を除去 Melt 2 ; スラグを除去後 , Melt 1 で得た V と他の合金を 溶解し脱酸

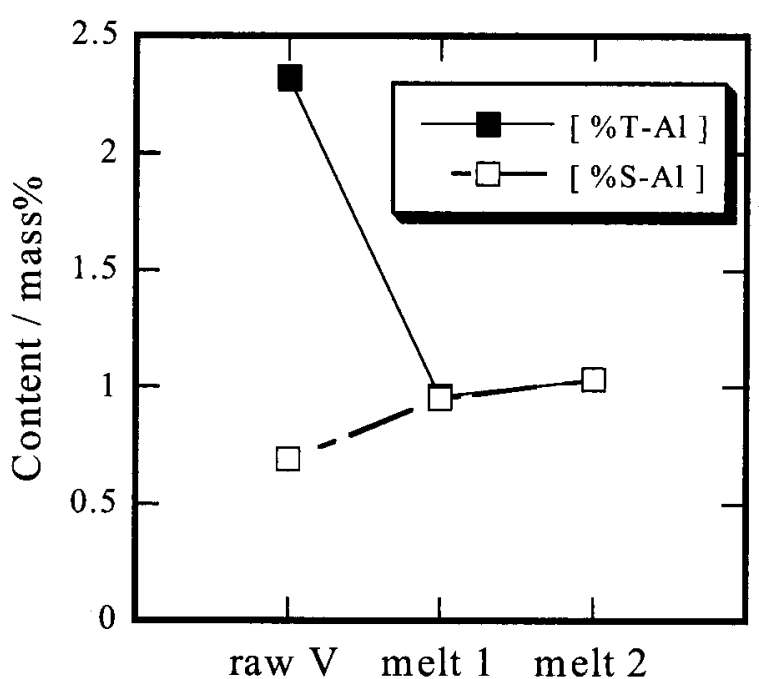

Fig.13. Al behavior of double-melt process.

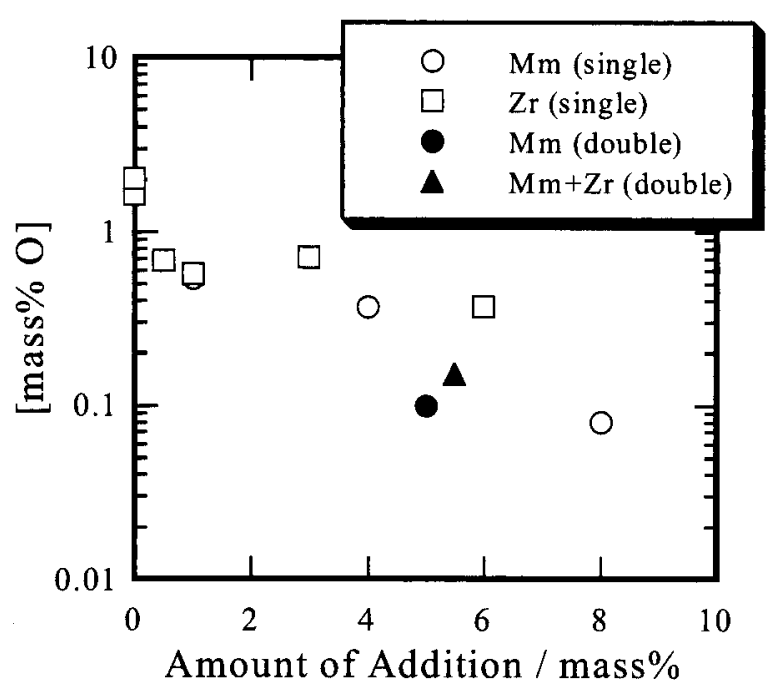

Fig.14. Deoxidization by double-melt process (single; single melting process, double; new double melting process).

上記のプロセス (以下, ダブルメルト (double-melt) 溶解 と称す) で TiCrVMn を製造した。

Fig.13 にこの方法での Al の挙動を示す . 第一段階のス ラグ精錬で T-Al が大幅に減少していることがわかる．S$\mathrm{Al}$ の上昇は低く抑えられ， $\mathrm{Al}_{2} \mathrm{O}_{3}$ の還元は起こっていない ことがわかる.最終的には $\mathrm{Al}$ 量は $0.9 \%$ まで低減された . Fig.14にMelt 2 での脱酸結果を示す .Melt 2 では一層の酸 素低減をねらい $\mathrm{CaO}-\mathrm{CaF}_{2}$ 系のスラグを用いた . 弚の結果 酸素は $0.09 \%$ まで低減できた . Fig.4, 5 に示すようなシン グルメルトプロセスと比較すると, 少ない量の脱酸剂で低 酸素化が実現できる . 


\section{3 酸素の挙動}

本研究では $\mathrm{Mm}$ および $\mathrm{Zr}$ を用いて脱酸を行なった。光

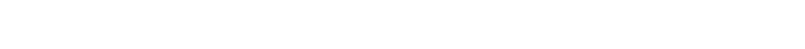
る .ここでは脱酸元素がどの程度脱酸に寄与したかを以下 の方法で算出した .

脱酸元素が実際に酸素と結びついた量を算出するには， 脱酸元素添加前のメタル中の酸素濃度を知る必要がある . 前述したように今回の実験では酸素は $\mathrm{Al}_{2} \mathrm{O}_{3}$ として存在す る部分が多くあるため, まずメタルに溶存する酸素濃度 (以下，S-O) を以下の方法で推定した .

$[\mathrm{S}-\mathrm{O}]=($ 溶解前の $\mathrm{T}-\mathrm{O})-\left(\mathrm{Al}_{2} \mathrm{O}_{3}\right.$ 中の $\left.\mathrm{O}\right)$

$=($ 溶解前の $\mathrm{T}-\mathrm{O})-(\Delta \mathrm{T}-\mathrm{Al}) \times(3 / 2) \times\left(\mathrm{M}_{\mathrm{O}} / \mathrm{M}_{\mathrm{Al}}\right) \cdots(2)$

ここで, $\Delta \mathrm{T}-\mathrm{Al}$ は T-Al の減少量を，M は原子量を表す， よって実際に脱酸元素による脱酸量 $\Delta \mathrm{O}_{\mathrm{M}}$ は以下のように なる。

$\Delta \mathrm{O}_{\mathrm{M}}=[\mathrm{S}-\mathrm{O}]-\left[\mathrm{O}_{\mathrm{e}}\right]$

ここで $\mathrm{O}_{\mathrm{e}}$ は脱酸後の全酸素濃度を表す．このように算出 した脱酸量 $\Delta \mathrm{O}_{\mathrm{M}}$ と脱酸元素添加量の関係を Fig.15 に示 す . 図から, 添加量の増加とともに脱酸量は増加している ことが分かる。なお図中には添加した $\mathrm{Mm}$ および $\mathrm{Zr}$ が全 て酸化物となると仮定して計算した理論脱酸量を線で示 した .

$\mathrm{Mm}$ は実際には $\mathrm{Ce}, \mathrm{La}, \mathrm{Nd}$ 等の希土類の混合物であるが 原子量はいずれの元素も 140 に近いので ,Mm を仮想的に 一つの元素と考える . 図中には $\mathrm{Mm}$ の酸化物が $\mathrm{Mm}_{2} \mathrm{O}_{3}$ の 形式となる場合と, $\mathrm{MmO}_{2}$ の形式となる場合の両方の計算 結果を示してある.図中のプロットと計算結果を比較する と, $\mathrm{MmO}_{2}$ の方が近くなっているため 2 価の酸化物になっ ているものと推察される.また，全体的に見ると実験値か ら計算した値は理論值の直線より上にある これは実際に は脱酸元素以外の元素でも脱酸が起こっていることを表 し , TiCrVMn で Mm 等の脱酸元素の添加量が少ない場合 にはTiによる脱酸がかなり起こっているものと思われる

また Fig.15 から今回開発したダブルメルトプロセスの $\mathrm{Mm}$ による脱酸量はほほ理論值と等しくなっていること がわかる.つまりこのプロセスでは実際の製造に際し必要 な $\mathrm{Mm}$ 添加量を精度良く計算することが可能となる．

\section{4 粗 V からの精錬による低 Al, 低 O 化 の効果}

今回最終的なダブルメルト工程により製造した TiCrVMn の水素吸蔵特性 (P-C-T 曲線) をFig.16 に示す。 図から有効水素吸蔵量は約 2.0 mass\% と読みとれる.高純 度 V を原料にして今回と同じレビテーション溶解炉で製 造した場合の有効水素吸蔵量は現状のベスト条件で 2.2

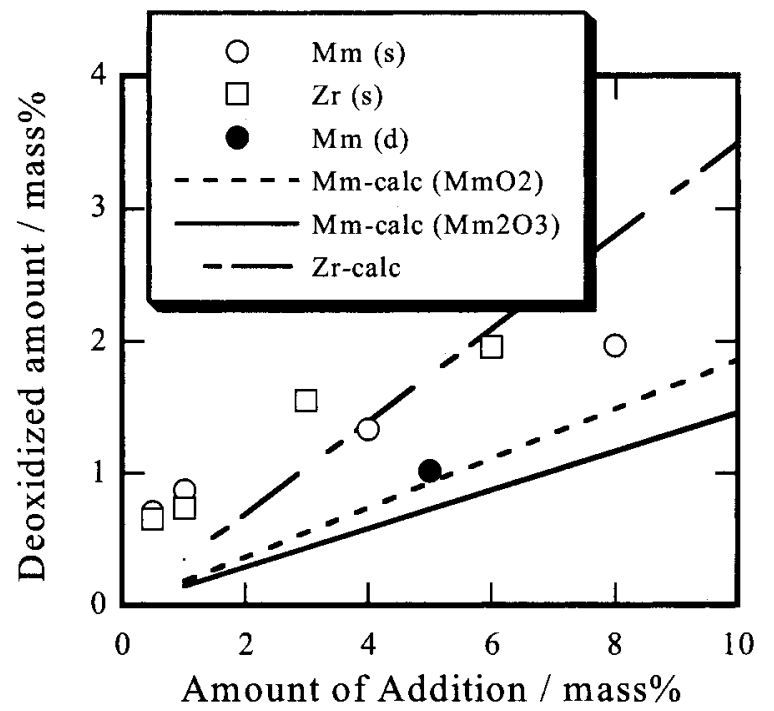

Fig.15. Deoxidized amount by Mm or Zr (s; single, d; double, -calc; calculated value of deoxidized amount).

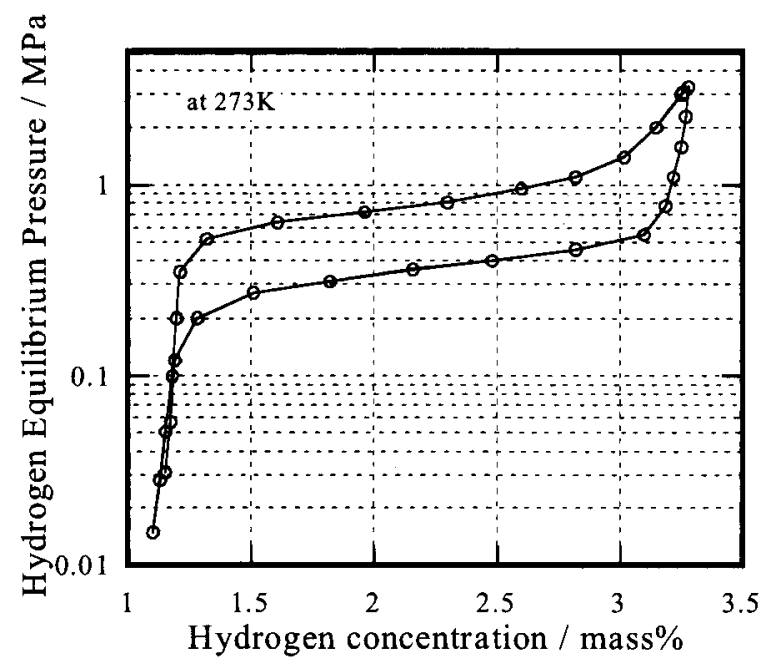

Fig.16. PCT curve for $\mathrm{V}-7.3$ mass $\%$ Ti-15 mass $\%$ Cr-2.4 mass $\%$ $\mathrm{Mn}-1.0$ mass\%Al-0.1 mass\% O produced by new double-melt process.

mass\% であるので,今回得られたサンプルの水素吸蔵量は 高純度 V スタート材と同レベルの高い水準を有している ことが分かった .

\section{6 . 結 言}

(1) 粗 V(Al-V95) 合金中をコールドクルーシブルでのスラ グを用いた脱酸精錬を行なうことにより $\mathrm{Al}$ とをを低減し， 水素吸蔵合金用の $\mathrm{V}$ 原料を製造するプロセスを開発した . (2) 粗 V 中の $\mathrm{Al}$ は酸化物の状態で多く残留しているため, $\mathrm{CaO}$ 系のスラグを用いて $\mathrm{Al}_{2} \mathrm{O}_{3}$ の溶融スラグへの吸収除去 を行なった . 兴の場合, 溶融メタル中に酸素との親和力の 
高い Tiや Mm, $\mathrm{Zr}$ などが存在すると $\mathrm{Al}_{2} \mathrm{O}_{3}$ が還元されて $\mathrm{Al}$ としてメタル中に移行するため, スラグ精錬は困難にな る.したがって溶融 V のみでスラグ精錬を行なうことが 望ましい.

(3) 脱酸は $\mathrm{Mm}$ か効果が高く,酸素濃度 0.08 mass\% まで低 減できた．また $\mathrm{Mm}$ はV $\mathrm{V}$ 合金中にほとんど残留しないた め, Mm を含まない水素吸蔵合金の製造には適している．

(4) スラグによる粗 $\mathrm{V} 中 の \mathrm{Al}_{2} \mathrm{O}_{3}$ 除去と合金溶解およびMm による脱酸工程を分ける新たな TiCrVMn の水素吸蔵合金 の溶解プロセスを開発し,水素吸蔵合金として高い特性を 得ることに成功した。

\section{(文 献)}

1)長瀬石根, 大河内敬雄, 清水孝純: 電気製鋼, 72(2001), 91.

2)川端，吉永櫻井塚原，神谷，高橋 境，竹下栗山，石：日 本金属学会誌, 64(2000), 221.

3) O. N. Carlson, F. A. Schmidt and W. E. Krupp : J. Met., 3 (1984), 320.

4)出向井登:電気製鋼, 66 (1995), 76.

5)出向井登:チタン, 47 No. 1 (1999), 25.

6)M. Tsukahara, K. Takahashi, T. Mishima, A. Isomura and T. Sakai: J. Alloys Comp., 245(1996), 59. 